\title{
Comparative study on the dissipation of thiram in two type of soils at oil palm (Elaeis guineensis Jacq.) nursery
}

\author{
Zainol Maznah ${ }^{1 *}$, Muhamad Halimah ${ }^{1}$, Sahid Ismail², and Abd Aziz Nordiana ${ }^{3}$ \\ ${ }^{1}$ Malaysian Palm Oil Board, Product Development and Advisory Services Division, No. 6, Persiaran Institusi, Bandar Baru \\ Bangi, 43000 Kajang, Selangor, Malaysia. *Corresponding author (maznahz@ mpob.gov.my). \\ ${ }^{2}$ Universiti Kebangsaan Malaysia, Faculty of Science and Technology, 43600 Bangi, Selangor, Malaysia. \\ ${ }^{3}$ Malaysian Palm Oil Board, Biology Research Division, No. 6, Persiaran Institusi, Bandar Baru Bangi, 43000 Kajang, \\ Selangor, Malaysia.
}

Received: 6 September 2017; Accepted: 12 December 2017; doi:10.4067/S0718-58392018000100086

\begin{abstract}
The dithiocarbamate fungicide thiram is extensively used in oil palm (Elaeis guineensis Jacq.) nurseries for protecting oil palm seedlings from diseases caused by Melanconium, Glomerella and Rhizoctonia sp. The factors affecting thiram dissipation were studied under tropical conditions at two experimental sites situated in oil palm nurseries with two soil types namely: Clay loam and sandy clay loam. The field experimental plots were treated with thiram at two dosages (using the knapsack sprayers) (1) at the recommended dosage (25.6 $\mathrm{g}$ ai plot $\left.^{-1}\right)$ and (2) at double the recommended dosage $\left(51.2 \mathrm{~g}\right.$ ai $\left.\mathrm{plot}^{-1}\right)$. Thiram residue was detected in the sandy clay loam and clay loam soils on treatment day ( 0 day) and from 1 to $3 \mathrm{~d}$ after treatment (DAT), respectively. The level of residue detected increased in soil depth. The results demonstrated that thiram dissipation was influenced by soil properties such as organic matter and clay content, and preferential flow was found to be the main pathway of thiram in the soil profile. The dissipation of thiram residue was observed in both the clay loam and sandy clay loam soils, to the depth of 50 and $30 \mathrm{~cm}$ of the soil profile, respectively, and the half-life was found to be less than $1 \mathrm{~d}$. These findings suggest that thiram is safe for use as a foliar application on oil palm seedlings due to its short life span in the soil and its low risk potential for groundwater contamination.
\end{abstract}

Key words: Mobility, oil palm nursery, preferential flow, thiram.

\section{INTRODUCTION}

The agricultural land use scenario in Malaysia has been continuously changing with time based on the performance and potential of crops. From 2013 to 2016, the area under oil palm (Elaeis guineensis Jacq.; Tan, 1983) plantations increased by $8.86 \%$ from 5.2 million to 5.7 million hectares (Malaysian Palm Oil Board, 2017). The oil palm nursery is the starting point in the palm oil supply chain (Halimah et al., 2010). During the early stages of seedling development, many pests and diseases could attack the seedlings and affect their growth rate and development. Therefore, the productivity and quality of oil palm seedlings produced depend on the nursery management practices.

The most frequently occurring diseases of oil palm seedlings are blast, leaf spots and anthracnose caused by Curvularia sp., Drechslera sp., Botryodiplodia sp., Melanconium spp., and Glomerella sp. (Chung and Sharma, 1999). Thiram and propineb fungicides have been found to be effective in controlling Curvularia seedling blight or nursery leaf spot infection of oil palm seedlings. Approximately $773068 \mathrm{~L}$ per year of thiram were reported to have been applied in oil palm nurseries from 2006-2010 and this constituted $99 \%$ of the total fungicide used in the 
oil palm nurseries. Therefore, with this high consumption, the usage of thiram in oil palm nurseries is expected to increase over the years as the oil palm acreages increase. Based on the survey, the dithiocarbamate group of fungicides namely thiram was the highest used among all pesticides used in the Malaysian oil palm plantations since 1999 (Ainie et al., 2007).

Besides the applicability of dithiocarbamates as strong analytical and electro-analytical chelating agents, some of the dithiocarbamates such as nabam, mancozeb, ferbam, ziram and thiram have been used as fungicides worldwide (Kanchi et al., 2014). Thiram (tetramethylthiuram disulphide) is a non-systemic dimethyl dithiocarbamate fungicide with preventive activity, has broad spectrum and is well-tolerated by crops and seeds (Thomas, 2001; Kanchi et al., 2014). Thiram has water solubility of $30 \mathrm{mg} \mathrm{L}^{-1}$ at $25^{\circ} \mathrm{C}$, melting point ranging from 155 to $156{ }^{\circ} \mathrm{C}$ (Sharma et al., 2003) and molecular mass of $240.44 \mathrm{~g} \mathrm{~mol}^{-1}$. Thiram has low to moderate persistence in the soil and is nearly immobile in clay soils and soils high in organic matter content. The major metabolites of thiram in the soil are copper dimethyldithiocarbamate, dimethylamine and carbon disulphide (EPA, 2004). Thiram is rapidly broken down by hydrolysis and photodegradation, especially under acidic conditions (Thomas, 2001). It was reported that the presence of thiram metabolites like dimethyl dithiocarbamate, bis(dimethyl carbamoyl) disulphide, bis(dimethyl dithiocarbamoyl) trisulphide and N-methyl-amino-dithiocarbamoyl sulphide was observed in the water and in the soils studied (Gupta et al., 2012a). Previously, Filipe et al. (2013) reported that the half-life of thiram applied at $2 \mathrm{mg} \mathrm{L}^{-1}$ in Milli-Q water was $28 \mathrm{~min}$ and that the commercial formulation components and humic substances (natural fulvic acids [FA] or commercial humic acids [HA]) slightly enhanced the photodegradation of thiram in aqueous solutions.

Compared to other pesticides, there is insufficient information on the behavior of thiram in soils, especially under tropical climatic conditions. In temperate soils, Valverde-Garcia et al. (1988) investigated thiram adsorption on different types of Almeria (East-Andalucia, Spain) soils and concluded that thiram adsorption appeared to be influenced by the soil organic matter content. More recently, studies have shown the effects of soil $\mathrm{Cu}$, commercial HA and organic amendments on thiram adsorption and desorption (Filipe et al., 2009; 2010; 2013).

There have been very limited reports on thiram behavior under field conditions either in temperate or tropical countries. One previous study on the thiram degradation was carried out under controlled laboratory conditions (Gupta et al., 2012b). Very recently, Liu et al. (2015) reported thiram dissipation and residual levels for potato cultivation in the open field. In the previous studies, we reported that thiram dissipates rapidly in the soil, water and from oil palm leaflets under humid tropical conditions due to high rainfall and thiram residue was detected in the soil profile to a depth of $50 \mathrm{~cm}$ (Maznah et al., 2012). Therefore, the objective of the present study was to identify the factors responsible for the downward movement and dissipation of thiram in different textured soil and its vertical distribution was monitored to evaluate the factors contributing to its dissipation in the soil profile. The new findings may help in reducing environmental and health risk problems.

\section{MATERIALS AND METHODS}

\section{Reagents and chemicals}

The analytical standard thiram (tetramethylthiuram disulphide; purity 99.8\%) was purchased from Dr. Ehrenstorfer (Augsburg, Germany). The commercial product (Ancom Thiram 80) was obtained from Ancom Crop Care Sdn. Bhd., Selangor, Malaysia. The chromatographic grade solvent acetonitrile and dichloromethane (LiChrosolv) were purchased from Merck, Darmstadt, Germany. Purified water was prepared using a Milli-Q water purification system (Millipore, Burlington, Massachusetts, USA). The dye tracer solution Brilliant Blue FCF (C.I.42090) used in the study, a food grade dye was purchased from SHT Bakery Ingredients Sdn Bhd (Puchong, Selangor).

\section{Instrumental analysis, standard preparation and validation method}

The HPLC Model 1200 (Agilent Technologies, Santa Clara, California, USA) equipped with a diode array detector (DAD) was used for determining the thiram content in the samples. The HPLC-DAD was fitted with an auto sampler and a $100 \mu \mathrm{L}$ loop. The chromatographic separation was performed using the analytical column, $\mathrm{C}_{18}, 25 \mathrm{~cm} \times 4.6$ $\mathrm{mm}$ id, $5 \mu \mathrm{m}$ (Ascentis, Supelco-581325-U, Bellefonte, Pennsylvania, USA). For the mobile phase acetonitrile and water were used in the ratio of $1: 1$ at the isocratic mode with a flow rate of $1.0 \mathrm{~mL} \mathrm{~min}^{-1}$. The UV wavelength was set at $230 \mathrm{~nm}$ while the injection volume was $20 \mu \mathrm{L}$. 
The analytical standard thiram $(0.05 \mathrm{~g})$ was dissolved in $50 \mathrm{~mL}$ acetonitrile to make up a stock solution of 1000 $\mu \mathrm{g} \mathrm{mL} \mathrm{m}^{-1}$. An intermediate stock solution at a final concentration of $100 \mu \mathrm{g} \mathrm{mL} \mathrm{m}^{-1}$ was prepared by dilution of $1.0 \mathrm{~mL}$ of the stock solution with acetonitrile in a $100 \mathrm{~mL}$ volumetric flask. A range of concentrations containing 1, 2, 4, 6 and $10 \mu \mathrm{g} \mathrm{mL} \mathrm{m}^{-1}$ was prepared by diluting the appropriate amount of the intermediate stock solution with acetonitrile in separate $10 \mathrm{~mL}$ volumetric flasks to obtain standard working solutions. All the standard solutions were stored in the freezer at $-20^{\circ} \mathrm{C}$, prior to analysis.

Prior to analysis of the treated soil samples from the field, the limit of detection (LOD), limit of quantification (LOQ) and recovery studies were determined. For the recovery study, fresh soil samples were fortified with known amounts of the analytical standard thiram. One $\mathrm{mL}$ of the standard thiram solutions was added to $10 \mathrm{~g}$ soil to obtain the final spiked concentrations of $1.0,0.5$, and $0.25 \mathrm{mg} \mathrm{kg}^{-1}$. Each concentration was replicated five times. The method for extraction of thiram from soil samples were carried out in accordance with the method described by Maznah et al. (2012).

\section{Field experiment}

The study was conducted at two oil palm nurseries located at two experimental sites, namely Sungkai in Perak and Labu in Negeri Sembilan, Malaysia. The oil palm nursery at Sungkai is owned by RISDA Semaian dan Landskap Sdn. Bhd. (RSSB) and is located at coordinates $03^{\circ} 18^{\prime} \mathrm{N}$ and $101^{\circ} 17^{\prime} \mathrm{E}$. Meanwhile, the nursery at Labu belongs to Sime Darby Sdn. Bhd. and is situated at coordinates $02^{\circ} 45^{\prime} \mathrm{N}$ and $101^{\circ} 49^{\prime} \mathrm{E}$.

The soil samples collected from the oil palm nurseries at Sungkai and Labu were classified as the clay loam soil and sandy clay loam soil, respectively. Fresh soil samples from 0-10, 10-20, 20-30, 30-40, and 40-50 cm were collected air-dried and ground to pass through a $2 \mathrm{~mm}$ sieve prior to analysis. According to the USA Soil Taxonomy classification, the soil types at Sungkai and Labu were identified as Inceptisols and Ultisols, respectively. The chemical and physical properties of the soils studied are shown in Table 1. Analyses for soil properties were carried out using standard methodology and procedure. Table 2 shows clay mineral properties obtained from each layer soils studied using X-ray diffraction (XRD) analysis.

Table 1. Chemical and physical properties of the two soils studied.

\begin{tabular}{lcc}
\hline Location & Sungkai & Labu \\
\hline Soil types (USDA) & Inceptisols & Ultisols \\
Texture & Clay loam & Sandy clay loam \\
Sand, \% & 30.90 & 50.75 \\
Silt, \% & 31.73 & 28.32 \\
Clay, $\%$ & 37.36 & 20.93 \\
pH & 4.73 & 5.52 \\
Organic C, $\%$ & 1.12 & 4.16 \\
Organic matter, \% & 3.91 & 14.52 \\
CEC, meq $100 \mathrm{~g}^{-1}$ & 7.32 & 13.35 \\
\hline
\end{tabular}

CEC: Cation-exchange capacity.

Table 2. Clay minerals properties of subsoil layers of the soils studied.

\begin{tabular}{|c|c|c|c|c|c|}
\hline Location & Soil depth & Kaolinite & Quartz & Gibsite & Muscovite \\
\hline & $\mathrm{cm}$ & 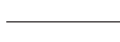 & 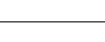 & . & $\bar{L}$ \\
\hline \multirow[t]{5}{*}{ Sungkai } & $0-10$ & 25.20 & 38.70 & 12.80 & 23.40 \\
\hline & $10-20$ & 16.20 & 61.10 & 10.80 & 11.90 \\
\hline & $20-30$ & 26.20 & 40.50 & 13.30 & 20.00 \\
\hline & $30-40$ & 32.20 & 30.40 & 12.30 & 25.10 \\
\hline & $40-50$ & 32.10 & 15.90 & 9.60 & 42.30 \\
\hline \multirow[t]{5}{*}{ Labu } & $0-10$ & 12.70 & 79.10 & 8.30 & NF \\
\hline & $10-20$ & 30.90 & 53.70 & 15.50 & NF \\
\hline & $20-30$ & 17.00 & 73.80 & 9.20 & $\mathrm{NF}$ \\
\hline & $30-40$ & 26.10 & 62.30 & 11.60 & NF \\
\hline & $40-50$ & 38.70 & 48.50 & 12.90 & NF \\
\hline
\end{tabular}

NF: Not found. 
The experimental plots in two sites were approximately 0.5 ha each and contained 5 to 11 -mo-old oil palm seedlings. The polybags used were $38 \mathrm{~cm} \times 46 \mathrm{~cm}$ and made of black UV stabilized polyethylene. Oil palm seedlings were planted in the center of each of the polybags and the bags were arranged at $0.9 \mathrm{~m} \times 0.9 \mathrm{~m} \times 0.9 \mathrm{~m}$ (measured center to center) to achieve an equidistant triangular spacing. The study was conducted at nurseries that used the double-stage nursery method. Watering was normally done twice daily before 11:00 $\mathrm{h}$ and after 16:00 $\mathrm{h}$ using the overhead sprinkler system (OSS). Both nurseries had a systematic drainage system or bunds to allow excess water to flow into the collection pond.

The treatments in the plot were arranged in a randomized block design (RBD) with three replicates. The plot was divided into nine sub-plots $\left(24.3 \mathrm{~m}^{2}\right)$ to accommodate three treatments; namely the manufacturer's recommended dosage (R1), double the recommended dosage (R2) and the control (R0, sprayed with water) (Figure 1). Each plot consisted of about \pm 150 oil palm seedlings, separated from the adjacent plots by a buffer zone of two rows of seedlings. The commercial thiram fungicide was applied using a knapsack sprayer (with nozzle nr 5) at a spray volume of $16 \mathrm{~L} \mathrm{plot}^{-1}$. The dosage applied was 25.6 and $51.2 \mathrm{~g}$ ai plot ${ }^{-1}$, following the manufacturer's recommended dosage and double the recommended dosage (as specified on the label).

Figure 1. Layout of the experimental plots at Labu and Sungkai oil palm nurseries.

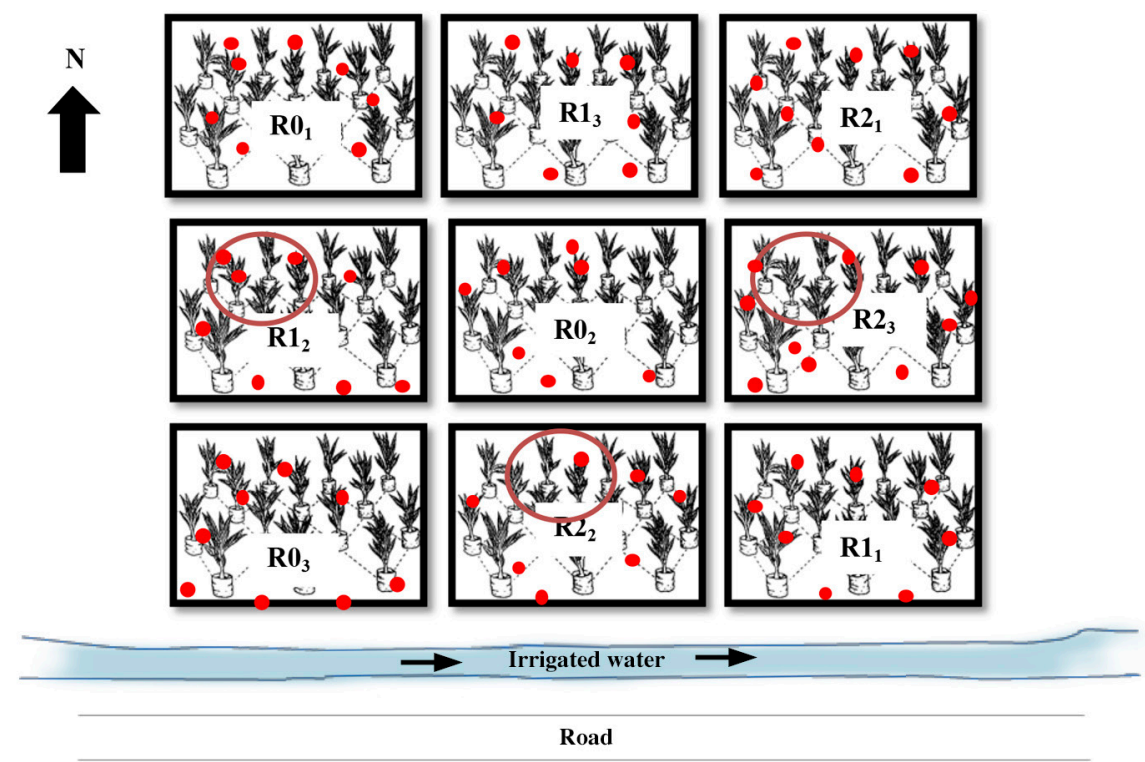

R0: Blank treatment; R1: recommended dosage; R2: double the recommended dosage; Dye experiment location; $\bullet$ soil sampling spot

\section{Soil sampling}

Soil samples were collected randomly from each plot at five points, using an auger set at different depths namely 0-10, 10-20, 20-30, 30-40, and 40-50 cm. The samples were collected as follows: day -1 (the day before treatment), 0 (6 $\mathrm{h}$ after spraying), and at 1, 3, 5, 7, 14, 21 and $30 \mathrm{~d}$ after treatment (DAT). After sampling, the holes were filled with fresh soil from non-treated areas and the areas were marked to avoid resampling at the same area. Debris, stones, and weeds were removed from the soil samples before they were air dried at room temperature and passed through a $2 \mathrm{~mm}$ sieve. Then, $10 \mathrm{~g}$ soil were weighed before being stored at $-4{ }^{\circ} \mathrm{C}$.

\section{Dye tracer experiment}

The Brilliant Blue FCF dye was used as the tracer to investigate the leaching pathway of thiram in the soil profile. For tracing water in the vadose zone, various dyes were proposed and the most suitable was the Brilliant Blue FCF, which is an organic dye that is often used for tracer detection in the vadose zone hydrology studies (Alaoui and Goetz, 2008). Flury and Fluhler (1995) stated that Brilliant Blue FCF is absorbed by soil material, has good visibility against the color of the soil background, plus it has low toxicity. 
Three plot sites $(2.0 \mathrm{~m} \times 2.0 \mathrm{~m}$ each $)$ were established at the Sungkai and Labu oil palm nurseries. The plots were selected in areas where the surface was even (no slope) to minimize the runoff and where there was no vegetation. An infiltration aluminum single ring of diameter $0.59 \mathrm{~m}$ and width $0.3 \mathrm{~m}$ was used. It was pushed into the soil to about $0.05 \mathrm{~m}$ with minimum soil disturbance and then, the inner diameter was filled with the $20 \mathrm{~L}$ Brilliant Blue FCF solution $\left(2 \mathrm{~g} \mathrm{~L}^{-1}\right)$. The plot was covered by canvas to prevent the dye from being washed away by rain. The experiment was carried out in triplicate. The vertical soil profile was carefully examined and photographed $3 \mathrm{~d}$ after treatment to visualize the dye distribution and penetration.

\section{Statistical analysis}

All experiments in the study were independently performed three times. The data shown in the figures and tables were the mean of five replicates (means $\pm \mathrm{SD}$ ).

\section{RESULTS AND DISCUSSION}

\section{Method validation}

The calibration curve for thiram was obtained by plotting the peak area against the concentration of the standard working solutions of concentration ranging from 1.0 to $10.0 \mu \mathrm{g} \mathrm{mL} \mathrm{m}^{-1}$. The linear regression $\left(\mathrm{R}^{2}\right)$ was found to be 0.999 and the equation derived from the calibration area data was $y=152.3 x-36.69$, where $y$ was the area of thiram obtained from the HPLC-DAD analysis and $x$ the concentration of thiram in $\mu \mathrm{g} \mathrm{mL}^{-1}$. A previous study showed that the limit of detection (LOD) and limit of quantification (LOQ) were 0.1 and $0.3 \mathrm{mg} \mathrm{kg}^{-1}$, respectively (Maznah et al., 2012). The repeatability of retention time and peak area was obtained for seven injections of thiram on the same day with RSD values of $0.51 \%$ and $4.17 \%$, respectively. The reproducibility and linearity of the injection technique were, therefore, acceptable. The extraction efficiency of the method was evaluated by conducting the recovery studies. The recovery levels of thiram from the soil ranged from $79.13 \%$ to $89.20 \%$ at fortified concentrations of 1.0 , 0.5 and $0.25 \mathrm{mg} \mathrm{kg}^{-1}$. The RSD values obtained ranged from $0.64 \%$ to $3.52 \%$.

\section{Dissipation of thiram residue in the soil}

The leaching of the thiram residue in the two soil types was investigated under field conditions for both the recommended and double the recommended dosages. Table 3 shows the concentration of thiram residue in the soil profile detected in the sandy clay loam soil at the Labu oil palm nursery. The results indicated that the residue of thiram was only detected on day 0 (immediately after treatment). At 3 DAT no residue was detected. The total

Table 3. The residues of thiram detected in the soil at Labu oil palm nursery.

\begin{tabular}{cccc}
\hline \multirow{2}{*}{$\begin{array}{c}\text { Day after } \\
\text { treatment }\end{array}$} & Depth & $\begin{array}{c}\text { Treatment at the } \\
\text { recommended dosage }\end{array}$ & $\begin{array}{c}\text { Treatment at double the } \\
\text { recommended dosage }\end{array}$ \\
\cline { 3 - 4 } & $\mathrm{cm}$ & \multicolumn{2}{c}{ Concentration $(\mathrm{n}=5)$} \\
\hline & $0-10$ & $79.30 \pm 1.21$ & $129.34 \pm 1.69$ \\
0 & $10-20$ & $64.15 \pm 1.54$ & $90.82 \pm 3.56$ \\
& $20-30$ & $28.44 \pm 1.94$ & $38.73 \pm 1.76$ \\
& $30-40$ & $12.89 \pm 3.97$ & $33.42 \pm 1.70$ \\
& $40-50$ & $1.22 \pm 0.20$ & $22.08 \pm 0.63$ \\
1 & $0-10$ & ND* & ND \\
& $10-20$ & ND & ND \\
& $20-30$ & ND & ND \\
& $30-40$ & ND & ND* \\
3 & $40-50$ & ND & ND \\
& $0-10$ & ND* & ND \\
& $10-20$ & ND & ND \\
& $20-30$ & ND & ND \\
& $30-40$ & ND &
\end{tabular}

*ND: Not detectable $\left(<0.1 \mathrm{mg} \mathrm{kg}^{-1}\right)$. 
amount of thiram residue from the soil samples $(0-50 \mathrm{~cm})$ treated at double the recommended dosage was higher (314.39 $\mathrm{mg} \mathrm{kg}^{-1}$ vs. $186.0 \mathrm{mg} \mathrm{kg}^{-1}$ ) than those from the samples of the plots treated at the recommended dosage. The lowest concentration of thiram namely $1.22 \mathrm{mg} \mathrm{kg}^{-1}$ was detected at the $40-50 \mathrm{~cm}$ depth.

The concentration of thiram residue in the clay loam soil $(0-50 \mathrm{~cm})$ collected at the Sungkai oil palm nursery is presented in Table 4. The residue of thiram in both treatment plots was observed at day 0 (immediately after treatment), at 1 DAT and 3 DAT. After 5 DAT, thiram residue could no longer be detected (below LOD) at all depths of the soil profile $(0-50 \mathrm{~cm})$ for both treatment plots.

Table 4. The residues of thiram detected in the soil at Sungkai oil palm nursery.

\begin{tabular}{|c|c|c|c|}
\hline \multirow{2}{*}{$\begin{array}{l}\text { Day after } \\
\text { treatment }\end{array}$} & \multirow[b]{2}{*}{ Depth } & $\begin{array}{l}\text { Treatment at the } \\
\text { recommended dosage }\end{array}$ & $\begin{array}{l}\text { Treatment at double the } \\
\text { recommended dosage }\end{array}$ \\
\hline & & \multicolumn{2}{|c|}{ Concentration $(\mathrm{n}=5)$} \\
\hline & $\mathrm{cm}$ & $\longrightarrow \mathrm{m}$ & $\mathrm{g}^{-1}$ \\
\hline \multirow[t]{5}{*}{0} & $0-10$ & $14.34 \pm 2.34$ & $27.04 \pm 3.46$ \\
\hline & $10-20$ & $8.36 \pm 0.75$ & $12.15 \pm 2.71$ \\
\hline & $20-30$ & ND* & $0.35 \pm 0.53$ \\
\hline & $30-40$ & ND & ND* \\
\hline & $40-50$ & ND & ND \\
\hline \multirow[t]{5}{*}{1} & $0-10$ & $7.05 \pm 3.18$ & $16.18 \pm 1.57$ \\
\hline & $10-20$ & $0.67 \pm 1.71$ & $5.34 \pm 3.82$ \\
\hline & $20-30$ & ND* & ND* \\
\hline & $30-40$ & ND & ND \\
\hline & $40-50$ & ND & ND \\
\hline \multirow[t]{5}{*}{3} & $0-10$ & ND* & $0.84 \pm 4.31$ \\
\hline & $10-20$ & $0.22 \pm 0.23$ & $0.27 \pm 2.37$ \\
\hline & $20-30$ & ND & $0.34 \pm 2.36$ \\
\hline & $30-40$ & ND & ND \\
\hline & $40-50$ & ND & ND \\
\hline \multirow[t]{5}{*}{5} & $0-10$ & $\mathrm{ND}^{*}$ & ND* \\
\hline & $10-20$ & ND & ND \\
\hline & $20-30$ & ND & ND \\
\hline & $30-40$ & ND & ND \\
\hline & $40-50$ & ND & ND \\
\hline
\end{tabular}

*ND: Not detectable $\left(<0.1 \mathrm{mg} \mathrm{kg}^{-1}\right)$.

The effect of soil properties on the persistence of many pesticides in the soil under tropical conditions have been documented (Halimah et al., 2012; Maznah et al., 2012). The sandy clay loam soil contains high organic matter content (14.52\%) and CEC (13.35 meq $\left.100 \mathrm{~g}^{-1}\right)$, which may adsorb thiram and thus reduce its mobility. Valverde-Garcia et al. (1988) concluded that the absorption of thiram in the Almeria soils depends primarily on the organic matter content, followed by the clay content of the soil. The results of present study show that the total concentration of thiram in the sandy clay loam soil was higher than that in the clay loam soil, probably due to the soil characteristics. The sorption of pesticides to the soil is influenced by the physico-chemical properties of the particular pesticide, as well as the soil properties (Hall et al., 2015). Organic matter and clay content are known to influence the downward movement of pesticides in the soil profile (Oppong and Sagar, 1992; Ismail and Maznah, 2006). The clay loam soil has high clay content and thus a strong tendency to adsorb thiram as the soil moisture level was low. Therefore, the residues of thiram persisted much longer and the downward leaching process was less effective because of its greater adsorption. Furthermore, during the application of thiram, the soil surface was partially covered by Eleusine indica (L.) Gaertn. Therefore, it was not surprising that the mobility of thiram in the soil profile was low and it did not leach deeper than $30 \mathrm{~cm}$ into the soil.

\section{Dye tracer study}

A soil monolith $(30 \mathrm{~cm} \times 30 \mathrm{~cm} \times 60 \mathrm{~cm})$ was laid open and its vertical profile was photographed. High resolution photographs $(1360 \times 2048$ pixels $)$ of the profile were taken with a digital camera (Cyber-shot, Sony, Tokyo, Japan). Figures 2 and 3 show the vertical profile of the soil monolith in the sandy clay loam and clay loam soils, respectively. The Brilliant Blue FCF dye was observed from the depth of 0-50 cm in the sandy clay loam soil and 0-30 $\mathrm{cm}$ in the clay loam soil. The dye was evenly distributed in the top soil $(0-25 \mathrm{~cm})$ but only found in the root canals, cracks, 
Figure 2. Vertical profile of a soil monolith and image analysis in the sandy clay soil dye stained in the soil profile $(0-50 \mathrm{~cm})(A)$, dye stained at soil surface $0-25 \mathrm{~cm}(B)$, and dye stained through root channels $(C)$.

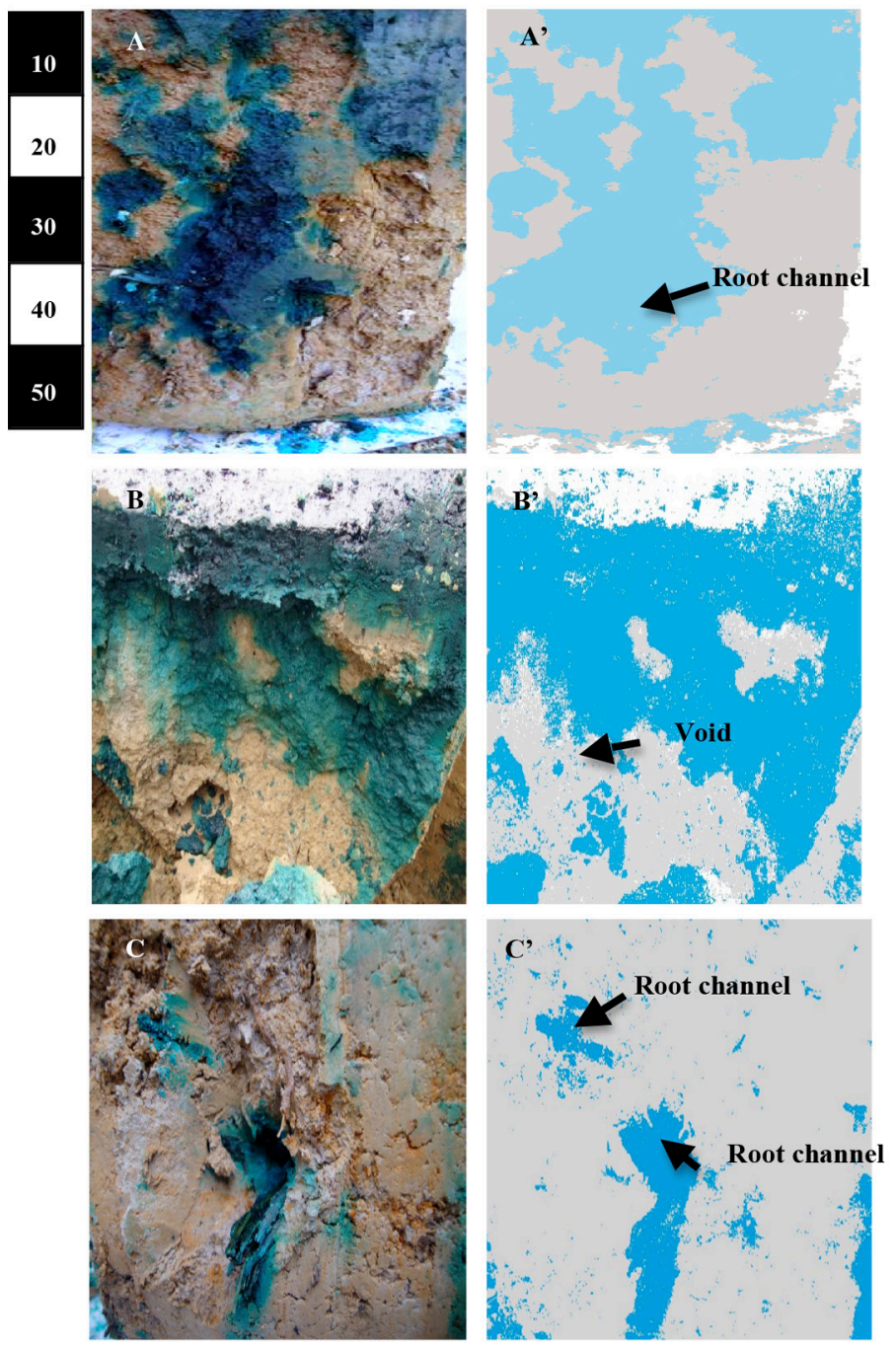

earthworm burrows and in the other macro pores of the sub soil $(>25 \mathrm{~cm})$. Most of the dye solution moved through former tree roots that were stretching from the upper layer to a lower depth in the soil.

Preferential water flow through macropores to the tiled drains plays an important role in the rapid transport of pesticides to the surface water (Tang et al., 2012). The preferential flow appeared to be significant in thiram transportation as seen in Figures 2 and 3. Many pores and cracks were found in the sandy clay loam and clay loam soils as well. The dye tracer infiltrated below the root zone to the depths of 50 and $30 \mathrm{~cm}$ in the sandy clay loam and clay loam soils, respectively. It should be noted that the sandy clay loam and clay loam soils showed completely different transport patterns due to the structure of the soil. The higher penetration of the dye in the sandy clay loam compared to that in the clay loam was because of the difference in the sand content. The main types of macrospores encountered included worm burrows, active and abandoned root holes and fractures in both soils. However, during the excavation process, the sandy clay loam was seen to have many soil pores and earthworms such as worms, grubs, millipedes, and shredders. Macrospores are large voids, often distinct in some manner in the soil matrix, and they can permit the preferential flow of water and contaminants through the soil profile (Cey and Rudolph, 2009). The preferential flow through the porous soils has been identified in previous field studies (Flury et al., 1994; Chai et al., 2009a; Maznah et al., 2015). The preferential pathways in structured soils may provide a short circuit from the soil surface not only to the surface waters via tiled drains but also to the groundwater (Tang et al., 2012). 
Figure 3. Vertical profile of a soil monolith and image analysis in the clay loam soil dye stained in the soil profile $(0-50 \mathrm{~cm})(A)$, Dye stained at soil surface $0-25 \mathrm{~cm}(B)$, and dye stained through root channels $(C)$.
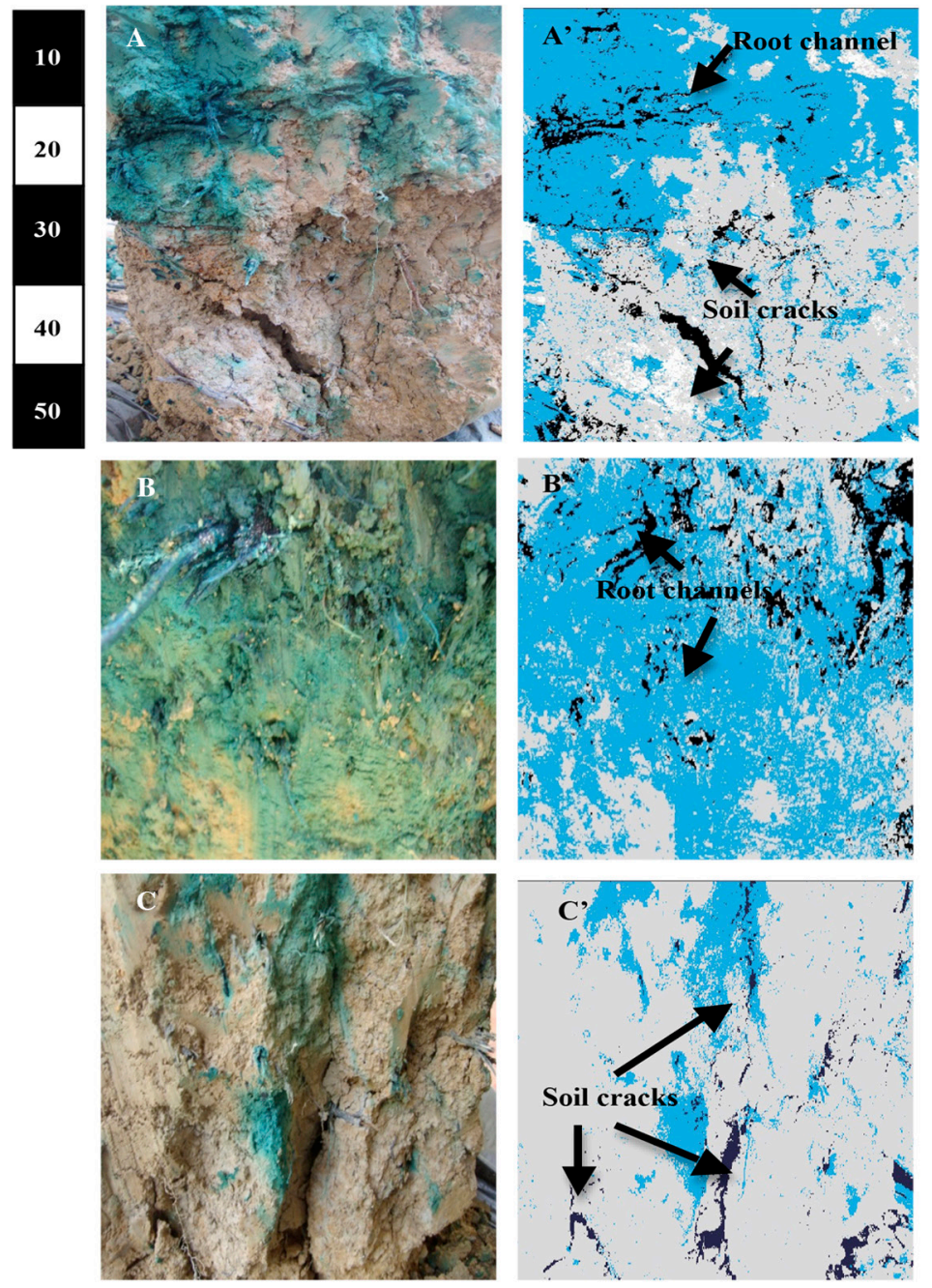

\section{Dissipation kinetics of thiram}

The first-order kinetic equation has been extensively used to describe the degradation and dissipation processes of many pesticides in the soil (Chai et al., 2009b; Maznah et al., 2015). In the present study, the dissipation kinetics of thiram in soil was performed by plotting the residue concentration against time and the dissipation of thiram was expressed in terms of half-life $\left(\mathrm{t}_{1 / 2}\right)$. The concentration of thiram remaining in the soil (Equation [1]) and the halflife of thiram (Equation [2]) were fitted by the first-order kinetics (Chai et al., 2013). The variables defined are as follows: $\mathrm{C}_{\mathrm{t}}\left(\mathrm{mg} \mathrm{kg}^{-1}\right)$ is the concentration at time $t, C_{0}$ the initial concentration, $k$ the rate constant and $t_{1 / 2}$ the half-life.

$$
\begin{aligned}
C_{t} & =C_{0} e^{-k t} \\
t_{1 / 2} & =\ln 2 / k
\end{aligned}
$$

However, there was a limitation in determining the half-life of thiram in the sandy clay loam soil as the thiram residue was only detected immediately after the treatment. The dissipation of thiram in clay loam soil appeared to follow the first-order kinetics (Figure 4). The equation derived from the dissipation curve was $y=-1.8604 \mathrm{x}+3.435$ with the $\mathrm{R}^{2}$ value of 0.9792 for the treatment at the recommended dosage. For double the recommended dosage, the value of $\mathrm{R}^{2}$ was found to be 0.9747 , and the equation was $y=-1.1372 \mathrm{x}+3.888$. The half-lives of thiram for treatment at the recommended and double the recommended dosage were 0.37 and $0.61 \mathrm{~d}$, respectively. 
Figure 4. Dissipation kinetics of thiram in clay loam soil.

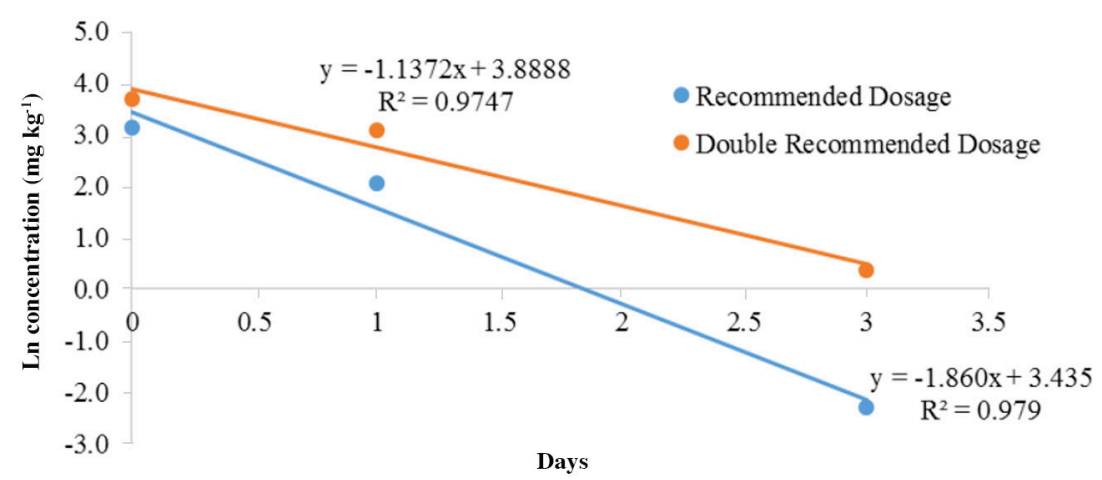

Pesticide transport processes in the field are complex and difficult to describe. Soil moisture, temperature, rainfall, and soil microbial activities are variables controlling the dissipation of pesticides under tropical conditions. As expected, the dissipation of thiram under field conditions was rapid due to the high rainfall and hot sun received during the study period. During the experiment the total rainfall received at Labu and Sungkai were 236 and 276 $\mathrm{mm}$, respectively. The maximum and minimum air temperatures recorded were 28.4 and $25.9{ }^{\circ} \mathrm{C}$, respectively, and the mean humidity level was $80 \%$. It was reported that the dissipation of thiram depended on the nature of the medium and environmental conditions such as temperature and $\mathrm{pH}$ (Gupta et al., 2012b).

\section{CONCLUSION}

The results indicate that the downward movement of thiram in the field trial was influenced by soil properties such as organic matter and clay content. Organic matter and clay in the soil have a strong tendency to adsorb thiram thus, the downward movement processes are hampered. It is also suggested that preferential flow may also contribute to the transport of thiram in the soil profile despite the fact that the structure of the soil under humid conditions supports a high population of soil microorganisms. The results showed that thiram dissipation of under tropical conditions is rapid as the half-life is less than 1 day. The results of the present study have implied that the application of thiram in oil palm nurseries will not adversely affect the environment as it has a very short half-life.

\section{ACKNOWLEDGEMENTS}

Sincere thanks are extended to the Director-General MPOB for permission to publish the paper. Thanks are also due to the technical staff at the Pesticides Laboratory, MBT laboratory, MPOB and MPOB-UKM Research Station for their invaluable assistance. Special appreciation goes to management of RISDA Semaian dan Landskap Sdn. Bhd. (RSSB), Changkat Sulaiman and Ladang Labu, Sime Darby Sdn. Bhd. for their support and assistance.

\section{REFERENCES}

Ainie, K., Tan, Y.A., Norman, K., and Yeoh, C.B. 2007. Pesticide application in the oil palm plantation. Oil Palm Bulletin 54:52-67.

Alaoui, A., and Goetz, B. 2008. Dye tracer and infiltration experiments to investigate macropore flow. Geoderma 144:279286. doi:10.1016/j.geoderma.2007.11.020.

Cey, E.E., and Rudolph, D.L. 2009. Field study of macropore flow processes using tension infiltration of a dye tracer in partially saturated soils. Hydrology Process 23:1768-1779. doi:10.1002/hyp.7302.

Chai, L.K., Mohd-Tahir, N., Hansen, S., and Hansen, C.B. 2009a. Dissipation and leaching of acephate, chlorpyrifos, and their metabolites in field soils of Malaysia. Journal of Environmental Quality 38:1160-1169. doi:10.2134/jeq2007.0644.

Chai, L.K., Norhayati, M.T., and Hansen, H.C.B. 2009b. Dissipation of acephate, chlorpyrifos, cypermethrin and their metabolites in a humid-tropical vegetable production system. Pesticide Management Science 65:189-196. doi:10.1002/ps.1667. 
Chai, L.K., Wong, M.H., and Hansen, H.C.B. 2013. Degradation of chlorpyrifos in humid tropical soils. Journal of Environmental Management 125:28-32. doi:10.1016/j.jenvman.2013.04.005.

Chung, G.F., and Sharma, M. 1999. Integrated pest and disease management and associated impact of pesticides. p. 83111. Malaysian Oil Palm Growers Council, Kuala Lumpur, Malaysia.

EPA. 2004. Thiram. United States Environmental Protection Agency (EPA), Washington D.C., USA. Available at https:// archive.epa.gov/pesticides/reregistration/web/pdf/0122fact_thiram.pdf (accessed February 2017).

Filipe, O.M.S.,Costa,C.A.E.,Vidal,M.M., and Santos,E.B.H.2013. Influence of soil copper content on the kinetics of thiram adsorption and on thiram leachability from soils. Chemosphere 90:432-440. doi:10.1016/j.chemosphere.2012.07.057.

Filipe, O.M.S., Vidal, M.M., Duarte, A.C., and Santos, E.B.H. 2009. Adsorption-desorption behavior of thiram onto humic acid. Journal of Agricultural and Food Chemistry 57:4906-4912.

Filipe, O.M.S., Vidal, M.M., Scherer, H.W., Schneider, R.J., Duarte, A.C., and Esteves, V.I. 2010. Effect of long term organic amendments on adsorption-desorption of thiram onto a Luvisol soil derived from loess. Chemosphere 80:293300. doi:10.1016/j.chemosphere.2010.04.003.

Flury, M., and Fluhler, H. 1995. Tracer characteristics of Brilliant Blues FCF. Soil Society of America Journal 59:22-27. doi:10.2136/sssaj1995.03615995005900010003x.

Flury, M., Fluhler, H., Jury, W.A., and Leuenberger, J. 1994. Susceptibility of soils to preferential flow of water: A field study. Water Resources Research 30:1945-1954. doi:10.1029/94WR00871.

Gupta, B., Rani, M., and Kumar, R. 2012b. Degradation of thiram in water, soil and plants: A study by high-performance liquid chromatography. Biomedical Chromatography 26:69-75. doi:10.1002/bmc.1627.

Gupta, B., Rani, M., Rahul, K., and Dureja, P. 2012a. Identification of degradation products of thiram in water, soil and plants using LC-MS technique. Journal of Environmental Science and Health, Part B 47(8):823-831. doi:10.1080/03 601234.2012.676487.

Halimah, M., Maznah, Z., Ismail, B.S., and Idris, A.S. 2012. Determination of hexaconazole in field samples of an oil palm plantation. Drug Testing and Analysis 4(Suppl. 1):112-117. doi:10.1002/dta.1351.

Halimah, M., Zulkifli, H., Vijaya, S., Tan, Y.A., Pua, C.W., Chong, C.L., et al. 2010. Life cycle assessment of oil palm seedling production (Part 1). Journal of Oil Palm Research 22:878-886.

Hall, K.E., Ray, C., Ki, S.J., Spokas, K.A., and Koskinen, W.C. 2015. Pesticide sorption and leaching potential on three Hawaiian soils. Journal of Environmental Management 159:227-234. doi:10.1016/j.jenvman .2015.04.046.

Ismail, B.S., and Maznah, Z. 2006. Adsorption-desorption and mobility of fenvalerate in three tropical agricultural soils. American-Eurasian Journal of Agriculture and Environmental Science 1:160-168.

Kanchi, S., Singh, P., and Bisetty, K. 2014. Dithiocarbamates as hazardous remediation agent: A critical review on progress in environmental chemistry for inorganic species studies of 20th century. Arabian Journal of Chemistry 7:1125. doi:10.1016/j.arabjc.2013.04.026.

Liu, S., Bai, A., Zhou, L., Yu, C., Li, Y., Fan, S., et al. 2015. Dissipation and residues of thiram in potato and soil. Journal of Chemistry 2015, Article ID 623847, 6 p. doi:org/10.1155/2015/623847.

Malaysian Palm Oil Board. 2017. Oil Palm Planted Area 2013, 2016. Available at http://bepi.mpob.gov.my (accessed March 2017).

Maznah, Z., Halimah, M., Ismail, B.S., and Idris, A.S. 2015. Dissipation of the fungicide hexaconazole in oil palm plantation. Environment Science Pollution Research 22(24):19648-19657. doi:10.1007/s11356-015-5178-z.

Maznah, Z., Ismail, B.S., and Halimah, M. 2012. Fate of thiram in an oil palm nursery during the wet season. Journal of Oil Palm Research 24:1397-1403.

Oppong, F.K., and Sagar, G.R. 1992. The activity and mobility of triasulfuron in soil as influenced by organic matter, duration and amount and frequency of rain. Weed Research 32:157-165. doi:10.1111/j.1365-3180.1992.tb01874.x.

Sharma, V.K., Aulakh, J.S., and Malik, A.K. 2003. Thiram: Degradation, applications and analytical methods. Journal of Environmental Monitoring 5:717-723. doi:10.1039/B304710E.

Tan, K.S. 1983. The botany of the oil palm. The Incorporated Society of Planters, Kuala Lumpur, Malaysia.

Tang, X., Zhu, B., and Katou, H. 2012. A review of rapid transport of pesticides from sloping farmland to surface waters: Processes and mitigation strategies. Journal of Environment Science 24(3):351-361. doi:10.1016/S10010742(11)60753-5.

Thomas, K.V. 2001. The environmental fate and behavior of antifouling paint booster biocides: A review. Biofouling 17:73-86. doi:org/10.1080/08927010109378466.

Valverde-Garcia, A., Gonzalez-Pradas, E., Villafranca-Sanchez, M., Del Rey-Bueno, D., and Garcia-Rodriguez, A. 1988. Adsorption of thiram and dimethoate on Almeria soils. Soil Science Society of America Journal 52:1571-1574. doi:10.2136/sssaj1988.03615995005200060009x. 